\title{
Decadencia y exotismo en una Venecia mitificada
}

\author{
Alejandro ArRoyo FERnÁndeZ \\ calamaroaaf@hotmail.com
}

Recibido: 30/09/2011

Modificado: $1 / 05 / 2012$

Aceptado: 08/05/2012

\section{Resumen}

Uno de los enclaves europeos mitificados por el cine y la literatura es la ciudad de Venecia. Es el marco sobre el que se desarrollan dos obras maestras de la literatura universal como El Mercader de Venecia y La Muerte en Venecia, donde se presta atención a aspectos fundamentales de la ciudad como el comercio, la estratificación social y el multiculturalismo. Mientras que la obra de Shakespeare presta atención al conflicto religiosocultural y al aspecto económico, Thomas Mann se centra en la decadencia de la ciudad y del continente europeo de principios del siglo $X X$. El dramaturgo inglés muestra una época próspera y de desarrollo económico, mientras que el autor germano destaca el ocaso del continente.

Palabras clave: decadencia, exotismo, agua, mascarada, entorno.

Title: Decadence and exoticism in the mythicized Venice

\section{Abstract}

Venice is one of the European cities mythicized in cinema and literature. It's the chosen place where two masterpieces of the literature take place, Merchant of Venice (1596) and Death in Venice (1911), where the focus is over fundamental aspects of the city such as trade, social structure and multiculturalism. However, Shakespeare presents the religious-cultural struggle and the economics field, while Thomas Mann focuses on the decadence spread over the city and the European continent in the early $20^{\text {th }}$ century. Both of them consider Venice as an icon of the period that they're living for. The English writer shows the economical development and a prosperous era, while the German author points out the twilight of the European continent.

Keywords: decadence, exoticism, water, masque, environment.

\section{Índice}

1. Introducción

2. La decadencia como elemento fundamental

2.1. El ocaso del continente europeo

2.2. El declive de una Venecia contaminada

2.3. El carácter nocivo del entorno

3. Mascarada

3.1. Mascarada shakesperiana

3.2. Transgresión de la mascarada

4. Exotismo veneciano

5. Conclusión 


\section{Introducción}

Venecia es uno de los enclaves más exóticos del continente europeo y el marco que conforman sus edificaciones y canales dota a la urbe de un carácter atemporal. El hecho de que sea la protagonista de dos obras tan distanciadas en el tiempo como El mercader de Venecia (1596) de Shakespeare y La muerte en Venecia (1911) de Mann es buena prueba de ello. Ambas describen la actividad de la ciudad, la presencia del símbolo veneciano de la máscara y cómo el exotismo propicia cierta promiscuidad sexual.

El presente artículo analizará las características y rasgos fundamentales de la Venecia shakesperiana y la Venecia de Thomas Mann para clarificar qué elementos mitifican a la ciudad italiana. Se plasmará la degradación de un marco socio-cultural que evoluciona negativamente desde la época shakesperiana a la de Mann y los conflictos que surgen entre las diferentes clases sociales. Además, se describirá el papel que desempeña la mascarada shakesperiana y la transgresión de la misma utilizada por Mann para presentar un juego simbólico del imaginario. Por último, se presentará el exotismo veneciano como el elemento que propicia la libertad sexual entre sus visitantes y los diferentes representantes de las clases sociales que aparecen en ambas obras.

\section{La decadencia como elemento fundamental}

El esplendor de Venecia en el siglo XVI y XVII es un elemento que favorece la mitificación de la ciudad ya que la convierte en un icono del desarrollo comercial europeo y del multiculturalismo. No obstante, la realidad en el siglo XX es bien distinta. La atmósfera de prosperidad es remplazada por el ocaso de la urbe y del continente europeo.

La decadencia del individuo es uno de los temas fundamentales de la novela de Mann y establece una conexión entre el declive de la vida de Aschenbach y la ciudad de los canales. El carácter pesimista de Aschenbach y su avanzada edad fundamentan su cuasi-depresiva psique. El marco social actúa como el elemento opresor del individuo, mientras que la búsqueda de un ambiente exótico y lejano se presenta como la vía de escape. Por contra, la Venecia shakesperiana no presenta un marco social asfixiante, más bien todo lo contrario. La ciudad no es lo que constriñe al individuo, el comportamiento individual está sugestionado por las costumbres, mitos y creencias de los habitantes. 


\subsection{El ocaso del continente europeo}

El veterano Aschenbach desea escapar de la decadente Múnich y busca un lugar exótico donde desarrollar su actividad artística. Sin embargo, la novela demuestra que la decadencia presente en Alemania se extiende por el resto del continente europeo. En este momento, el imaginario que presentan la Venecia shakesperiana y la de Mann distancia ambos enclaves. La ciudad de Shakespeare se fundamenta en una celeridad que proviene del multiculturalismo y de la actividad mercantil, mientras que la de Mann se caracteriza por ser un espacio en claro declive.

El hecho de que Mann identifique su ciudad de origen con un cementerio es una muestra de la visión que tiene el artista de las ciudades del norte de Europa: "Decidió esperar junto al Cementerio del Norte, el tranvía que habría de llevarlo directamente a la ciudad, la parada y sus alrededores estaban, por casualidad, totalmente desiertos" (Mann 1996: 18). Presenta su tierra natal como un territorio baldío y decrépito. Sin embargo, la marcha a Venecia no es una decisión coherente ya que años atrás tuvo que abandonar dicha ciudad por ser un enclave poco saludable. Además, el hecho de que esté infectada por la peste demuestra que es una decisión errónea. Mann identifica subjetivamente Venecia con una tierra caótica y esto favorece que Aschenbach la relacione de manera subconsciente con el ocaso del continente europeo. La descripción de la ciudad de los canales que aparece en el texto de Mann emana de un estado de ensoñación y confusión del protagonista.

Una especie de caos primigenio poblado de islas, pantanos y cenagosos brazos de río; entre una lasciva profusión de helechos, sobre una maraña de vegetación ubérrima, turgente y de disparatadas floraciones vio erguirse velludos troncos de palmera, próximos y lejanos. (Mann 1996: 20)

Aunque esta descripción obedece a un estado pseudo-onírico del protagonista de la novela, la atmósfera presentada no guarda relación con el imperio mercantil y el ambiente cosmopolita que presenta el autor inglés. Las connotaciones negativas relacionadas con el declive cultural europeo que invaden a Aschenbach le impiden relacionar Venecia con la prosperidad, de ahí, que él mismo se autosugestione perniciosamente. Por otro lado, al igual que en el texto shakesperiano, la actividad comercial es uno de los rasgos fundamentales de la ciudad italiana. Las autoridades están obligadas a guardar celosamente la información relacionada con la peste para asegurar los ingresos derivados del turismo.

El aspecto físico poco saludable de Tadzio es otro de los elementos que presentan el declive del continente europeo. Aschenbach nota su debilidad desde el primer encuentro con él: "Es 
enfermizo, probablemente no llegará a viejo" (Mann 1996: 79). Desde el punto de vista pesimista del escritor existe la posibilidad de que la pestilente ciudad acabe con la vida del joven. El momento de mayor peligro para él es el ataque de uno de sus compañeros que casi le arrebata la vida. Esta acción demuestra que no es Venecia per se lo que daña a la persona, sino el propio continente el que oprime al individuo hasta su fin.

Por todo esto, el texto de Mann presenta la agonía del territorio europeo, más que la del joven Tadzio o la del veterano Aschenbach. No hay ningún rincón de Europa donde el individuo esté seguro. El literato emigra a Venecia en un vano intento por escapar de su fatídico final. Sin embargo, recae en una ciudad que está invadida por la peste y por un hermetismo que impide saber con certeza qué está ocurriendo. El carácter determinista de la obra de Mann y la muerte del veterano artista evidencian la imposibilidad de escapar de un fatídico final que vigila y ataca a los personajes. No es relevante si el desenlace viene determinado por una enfermedad, por la ancianidad o por el ataque de otro individuo, porque todo esto evidencia la imposibilidad de escapar a la muerte.

La visión inicial de viaje como medida higiénica queda anulada por la atmósfera que el protagonista encuentra al llegar a su destino, por la transmisión de la peste y por la necesidad enfermiza de seguir a Tadzio. Jaime Fernández, en La ciudad de los extravíos, señala la imposibilidad de sobrevivir y el carácter destructivo del hombre al afirmar que:

La autodestrucción con la que Aschenbach paga su abandono al goce más contemplativo que empírico de la vida, supondrá la victoria final del norte, simbolizado en la figura del hombre-muerte de aspecto extranjero que al comienzo de la novela vio en la puerta del cementerio de Múnich. (Fernández 2010: 24)

Estos elementos presentan las características autodestructivas que posee el viaje de Aschenbach. No tiene sentido que decida escapar de un ambiente que le oprime para ir otra ciudad que fue dañina para él en el pasado. La única explicación posible sería que identifique el enclave con la liberación sexual. Por lo tanto, es cuestionable que este viaje sea un último intento para continuar con su actividad artística ya que la trama de la novela está envuelta en una atmósfera mortal y enfermiza.

\subsection{El declive de una Venecia contaminada}

El carácter comercial y cosmopolita de Venecia es un aspecto que propicia su mitificación. Shakespeare plasma una urbe que alcanza una prosperidad económica basada en el desarrollo comercial y donde la conformación del contexto socio-cultural obedece al estatus social 
y a la condición religiosa de los habitantes. Venecia es uno de los centros comerciales de la Europa de los siglos XVI y XVII, idea que defiende Holdernes en Shakespeare and Venice al describir la ciudad como: Venice is a market and an empire, a centre of trade and a bulwark of
Christian power. The talk is all of money, trade entrepreneurial
adventure, of ships and cargoes, silks and spices, of debt and credit,
risk and fortune. Rialto is, in the play as it was the historic Venice,
the centre of the city, the focal point of exchange where commercial
transactions are conducted, fortunes are made and lost; just as later
in the play the court-room provides a dramatic model to test Venice's
reputation for justice and equality before the law. (Holdernes 2010:
58)

Estas son las características que ayudan a la identificación de la ciudad en la época shakesperiana y marcan distancia con la visión de Mann. La actividad comercial propicia su desarrollo, y la coexistencia de varias razas y religiones en la ciudad muestra su pluralidad y cosmopolitismo. En la obra de Mann no aparece el conflicto racial y se describe minuciosamente la presencia de las distintas clases sociales del continente.

No hay degradación en la ciudad presentada por Shakespeare ya que, como se ha mencionado anteriormente, el florecimiento de la ciudad es directamente proporcional al desarrollo económico. Los conflictos presentes en la obra de Shakespeare obedecen a enfrentamientos raciales y mercantiles derivados de la convivencia entre varias culturas. El texto de Mann y el de Shakespeare presentan una interacción que no depende de la clase o raza. Además, la edad desempeña un papel primordial en el ámbito sexual de ambas obras. La temática homosexual de la obra del dramaturgo inglés aporta una diferencia evidente entre el mundo masculino y femenino: "We move from a world of men (the only female in Shakespeare's Venice is Jessica) to one dominated by women; and from a domain of trade to a demesne of landed property" (Holdernes 2010: 64). Los protagonistas interactúan con el mundo masculino y femenino independientemente de su condición sexual. Buena prueba de ello es que la tendencia homosexual de Antonio permanece en segundo plano y que las mujeres están disfrazadas de abogados en la mascarada final. El hecho de que la acción cambie de escenario en este punto de la obra, alternando la ciudad con el palacio de Portia, es otro detalle que demuestra la dualidad y el multiculturalismo venecianos.

En cuanto al mundo de hombres que representa la Venecia mercantil, hay que resaltar que el texto isabelino no muestra cuál es la actividad laboral de Bassanio, Lorenzo y Salarino. Únicamente se 
intuye que está más próxima al mundo elitista de los gentlemen que al mercantil. Esta teoría se sustenta en el hecho de que, aunque no tiene el dinero necesario, Bassanio opta a ser uno de los pretendientes de Portia. Por tanto, se establece que la posición social viene determinada por la influencia de la alianza económicomercantil.

La pluralidad racial de la Venecia shakesperiana consolida la presencia de varias culturas. El comportamiento de Shylock refuerza las líneas que delimitan el marco religioso-cultural de la Venecia de Shakespeare al decir:

Yes, to smell pork, to eat of the habitation / which your Prophet the Nazarite conjured the devil into: / I will buy with you, sell with you, walk / with you, and so following / but I will not eat with you, / drink with you, nor pray with you. What news on the / Rialto, who is he comes here? (Shakespeare 2001: 34)

El enfrentamiento entre los representantes de las diferentes razas y religiones es uno de los elementos que perturba el equilibrio de la ciudad. Shylock se considera una de las personas influyentes en esta sociedad debido a su actividad comercial, de ahí que afirme: "He [Antonio] hates our sacred Nation" (Shakespeare 2001: 34). Esto presenta una lectura económica subyacente que hace referencia a una sociedad veneciana fundamentada en préstamos y usureros. El enfrentamiento ideológico entre ambos desde el principio representa facetas opuestas en temas económicos, religiosos y culturales.

Por otro lado, tanto Mann como Shakespeare realizan una descripción verosímil del enclave y el marco social queda plasmado de manera extraordinaria, independientemente de la aparición o no de los estereotipos de la obra.

[...] Los lectores de ambos relatos saltan de la imagen de una ciudad próspera y cosmopolita a otra herida por la decadencia, por el culto museístico y por la convivencia interesada entre una población nativa empobrecida y la selecta minoría de acaudalados turistas centroeuropeos que la frecuentaban. (Fernández 2010: 8)

En definitiva, el texto de Mann presenta una ciudad cargada de connotaciones negativas donde la actividad comercial que le dio esplendor en una época anterior ha sido reemplazada por una enfocada al turismo. La sociedad veneciana de Shakespeare es un entorno donde el conflicto religioso-cultural y una economía basada en la usura tienen cabida. Por último, uno de los elementos que ayuda a la recepción de la obra en la época isabelina es que el protagonista y el antagonista de la obra son dos estereotipos fácilmente reconocidos en la sociedad de los siglos XVI y XVII. 


\subsection{El carácter nocivo del entorno}

La presencia de canales y el carácter de pseudo-isla definen dicho enclave, de ahí que la relevancia del agua en la mitificación de la ciudad sea incuestionable. Este elemento no pasa desapercibido ni en el texto de Mann ni en la obra de Shakespeare, donde desempeña un papel primordial.

El agua es un elemento fundamental para la compresión de la novela de Mann porque aporta una serie de connotaciones negativas que conectan con el decaimiento de la cultura europea. La llegada de Aschenbach a la ciudad se produce en barco, no podía de ser de otra manera, y el gondolero que aparece en la escena remite a la figura mitológica de Caronte. El viaje en bote guarda semejanza con el trayecto sobre el río Aqueronte que desemboca en el trágico final. Este elemento permite la identificación de la ciudad de Venecia con el destino donde el autor alemán encontrará la muerte. Cuando el artista llega a su hotel intenta despejar el aire viciado de la habitación pero consigue el efecto contrario: "Al abrir sus ventanas, Aschenbach creyó percibir el fétido olor de la laguna" (Mann 1996: 43).

Esto aporta varias lecturas que revelan el deterioro de la ciudad y que conectan el estado anímico del artista y el ocaso de la urbe. El olor despierta en él unas sensaciones nauseabundas que le recuerdan a la primera vez que tuvo que huir de Venecia. Su visión deprimente de la vida hace que identifique el agua con el elemento que propicia la llegada de infecciones y de la muerte. El agua y la multitud de canales de la ciudad conforman un circuito cerrado del que es difícil salir. Si a esta identificación del agua como un elemento dañino para el entorno se le une la presencia de Caronte, el resultado es la identificación de Venecia con una ciudad-cementerio.

La acción del agua en la novela de Thomas Mann es devastadora. Es interesante que la peste que está asolando Venecia sea el "cólera seco", es decir, una enfermedad que afecta letalmente al cuerpo humano. Tal y como aparece descrita en el texto de Mann: "el cuerpo es incapaz de evacuar el líquido segregado en abundancia por los vasos sanguíneos" (Mann 1996: 81). Esta enfermedad genera gran cantidad de fluido en el interior del cuerpo y lo colapsa dando como resultado la muerte. La putrefacción que emana del agua de Venecia se filtra en el cuerpo a través de la peste y lo ahoga. Además, el carácter dañino del entorno veneciano se incrementa simbólicamente si se tiene en cuenta que el término "cólera" proviene del griego khólera (canal). Esta acción destructiva no está presente en la obra de Shakespeare donde el agua es el elemento que propicia el éxito de las actividades comerciales de Antonio. No obstante, este hecho varía según avanza la acción. El retraso de la llegada de sus navíos con las ganancias necesarias para pagar la deuda a Shylock muestra el carácter traicionero del mar. 


\section{Mascarada}

La presencia del carnaval de máscaras es otro de los elementos que ayudan a la mitificación de la ciudad. Por otro lado, la inclusión de mascaradas y juegos que favorezcan el enlace matrimonial son elementos utilizados por Shakespeare y el teatro isabelino. Estos recursos cómicos aportan el elemento lúdico, rebajan la carga dramática de la obra y desencadenan el final feliz.

La máscara como tal no aparece en la obra de Mann, pero sí cierta confusión por la apariencia singular de algunos personajes a lo largo de la obra. Con esta técnica, Mann presenta en su novela la transgresión de la clásica mascarada isabelina para la composición del carácter maléfico y desconcertante de los individuos.

\subsection{Mascarada shakesperiana}

Probablemente, el autor inglés elige el marco veneciano para la composición de su obra por la existencia de un conflicto religioso y económico, por la diversidad cultural presente en la ciudad y por la posibilidad de liberación sexual que transmite dicho enclave. Al principio de la obra hay contenido dramático relacionado con la imposibilidad del amor homosexual entre el joven Bassanio y el mercader Antonio. Sin embargo, la intensidad de la trama queda rebajada con la incursión de la mascarada que aporta el tono cómico y favorece que sea clasificada como una comedia isabelina. Shakespeare presenta una mascarada centrada principalmente en dos acciones: el juego de los cofres de Portia y una mascarada final donde las nobles se disfrazan de abogados. Como defiende Bregazzi en su obra Shakespeare y el teatro renacentista inglés, la presencia de estos elementos es una técnica recurrente en el teatro isabelino:

No obstante, en la comedia romántica inglesa, y sobre todo en la shakesperiana, el matrimonio no se presenta como un final feliz automático, ni como imposición, pues hay un énfasis muy marcado sobre el criterio de la mujer en la elección de compañero, en cómo ella le pone a prueba y le hace demostrar su idoneidad. (Bregazzi 1999: 51)

El juego de los cofres es el método seleccionado para escoger un pretendiente ideal para Portia. Las ansias y expectativas de los candidatos conectan de modo inconsciente con el material del que están fabricados los cofres. En dicha elección se evidencian una serie de estereotipos sociales dirigidos hacia los no cristianos por parte de los católicos.

Curiosamente Shakespeare endosa el pecado de la codicia a los dos infieles de la obra, el judío Shylock y el musulmán príncipe marroquí. Los no redimidos por Cristo yerran en su elección al inclinarse por las 
apariencias que encubren el engaño, guiados por la soberbia y la avidez. (Fernández 2010: 53)

No obstante, el cristiano tampoco queda libre de los estereotipos sociales ya que hay una identificación simbólica entre el cofre de plata y las actitudes narcisistas del pretendiente. La superioridad religiosa cristiana sobre la judía permite tildar con connotaciones negativas a los judíos, de hecho, destacan sus prácticas usureras. Sin embargo, el católico sale prácticamente indemne y únicamente resalta en él cierto carácter narcisista que proviene de su reflejo simbólico en el cofre. Si la elección del arcón de plata otorga a cada uno lo que se merece, de acuerdo con la inscripción contenida en el cofre, y el cristiano puede verse reflejado en él, significa que se merece a él mismo por encima de todo. La práctica de los matrimonios concertados es criticada con la incursión de este juego, ya que fundamentar la elección del esposo sobre esta acción no es una decisión coherente.

La mascarada es el elemento utilizado en la obra de Shakespeare para reducir la carga dramática del enfrentamiento entre Shylock y Antonio. El mercader está obligado a pagar a Shylock la deuda, pero el judío no acepta otro pago que no sea el de la "libra de carne". El conflicto religioso presente en esta comedia isabelina propicia que el católico Antonio y el judío Shylock interactúen como dos estereotipados antagonistas. El enfrentamiento entre ambos se transmite a otras esferas igualmente necesarias para la composición de la obra shakesperiana, ya que "la delirante fantasía de morir a manos de su enemigo religioso, Shylock, identificándose así con el primer mártir, Jesús, quien, según la vieja leyenda cristiana, murió en la cruz a manos también del mismo enemigo de Antonio" (Fernández 2010: 12), es una salida digna a la controversia que pudiera despertar el deseo carnal homosexual del mercader hacia la figura de Bassanio. En cualquier caso, esta comparación de Antonio con Jesús, aunque muestra el enfrentamiento religioso, es un tanto exagerada.

El judío está condenado por el mero hecho de no ser cristiano. No obstante, podría salvarse mediante la conversión de Jessica, de ahí que en el texto shakespeariano se mencione: "If e'er the Jew her Father come to heaven / It will be for his gentle daughter's sake; / And never dare misfortune cross her foot" (Shakespeare 2001: 48).

Esta salvación es posible porque la fe cristiana es inconmensurable desde un punto de vista católico. Sin embargo, la negación de Shylock dificulta el enlace matrimonial, aunque la decisión de Jessica ante la prohibición del encuentro es dar la espalda a su padre, pues le dice: "I have a Father, you a daughter Lost" (Shakespeare 2001: 51). Esta declaración conlleva una doble lectura ya que renuncia a su padre biológico y el hecho de que el término 
venga con mayúsculas remite al Padre Cristiano, es decir, al Dios de la Cristiandad al que se entrega a través de Lorenzo para salvar su alma.

En definitiva, Shakespeare utiliza la mascarada como un instrumento que rebaja el dramatismo de la escena. La incursión de las dos nobles disfrazadas de abogados resulta cómica para el lectorespectador. Además, el hecho de que sean nobles favorece su conocimiento de las leyes de la ciudad. El entretenimiento y la diversión del espectador es una de las funciones principales del teatro isabelino y ambas quedan satisfechas con la incursión de la mencionada mascarada.

\subsection{Transgresión de la mascarada}

Si la obra de Shakespeare presenta la típica mascarada isabelina para aportar el tono de comicidad y solucionar el conflicto religioso, la obra de Mann presenta una variación de esta técnica. La transgresión de la mascarada creada por Mann no presenta un disfraz per se, más bien es una identificación simbólica entre el individuo real y el individuo que representa. En La muerte en Venecia hay dos transgresiones evidentes de la mascarada shakesperiana: la aparición de un hombre de figura de diabólica en el camposanto y la de un anciano vestido de joven en la cubierta del barco.

La primera es la aparición cuasi-maléfica de un hombre desconocido al principio de la obra. La descripción del sujeto y del lugar donde se encuentra, el cementerio de la ciudad, atemorizan a Aschenbach. La aparición del cementerio es previa al comienzo del viaje y propicia la comparación de Múnich con una ciudadcementerio. Jaime Fernández en su obra La ciudad de los extravíos: Visiones venecianas de Shakespeare y Thomas Mann sostiene que:

El hombre de aspecto extranjero, recio y viril que Aschenbach ve aparecer al comienzo del relato en la puerta del cementerio de Múnich simboliza la muerte-norte, con sus tentadoras sugerencias de viajes a lugares exóticos. Antes de decidirse por Venecia, la mera visión de este enigmático personaje le incitará a salir de Múnich y emprender el viaje al sur, hacia el ardiente Adriático. Ya en la ciudad de los canales, Aschenbach es testigo de la aparición de la muertesur, encarnada en un viejo carcamal disfrazado de joven, que con sus bufonadas le muestra al visitante el sarcástico rostro de la muerte [....]. (Fernández 2010: 23)

Este es otro de los antagonismos presentes en la obra de Mann. La región alemana se presenta como un lugar seguro en el que desarrollar las actividades relacionadas con el estatus social que se le presuponen a Gustav y donde el marco de valores obliga a seguir un determinado patrón de conducta. En contraposición a esta seguridad 
está la presencia del siniestro personaje que demuestra la necesidad de escapar de la ciudad. Además, está el exotismo del Sur, la mascarada y lo amenazante que resulta un lugar en el que nada es lo que parece. A pesar de ser otro enclave europeo, simboliza un lugar lejano donde el decrépito poeta puede entregarse a su lado más dionisíaco. No obstante, la transgresión más evidente de la mascarada del teatro isabelino en la obra de Mann la encarna el anciano que aparece en la cubierta del barco disfrazado como un joven para poder relacionarse con los adolescentes. Aschenbach censura esta actitud al principio de la obra. Sin embargo, finalmente sucumbe a la tentación y termina por disfrazarse de la misma manera. La visión inicial del anciano es descrita en un período de ensoñación y es una muestra de la incursión del mundo onírico de Aschenbach dentro del mundo real. Esta segunda yuxtaposición de imágenes entre el mundo racional y el irracional presenta a un Gustav que se mueve entre dos planos simultáneamente y que no es capaz de reconocer si lo que está viendo es real o no. No obstante, este artificio revela que Aschenbach ha descubierto el modo de traspasar las barreras que el marco ético ha establecido y que éste es el único modo de acercarse al deseado efebo. Sin embargo, "no sabe que la peste ha anidado en su organismo y que bajo el disfraz juvenil se camufla la muerte [...]" (Fernández 2010: 18).

Hay una conexión entre la decadencia de la ciudad y el veterano Aschenbach en este momento. Bajo la apariencia sana está la destrucción física del hombre, del mismo modo que bajo la atmósfera de normalidad que quieren trasmitir las autoridades venecianas está la peste. La transgresión de la mascarada shakesperiana se establece cuando la apariencia repulsiva del anciano que encontró disfrazado se convierte en su propio destino.

En cualquier caso, la máscara forma parte activa en la composición de ambas obras. En el texto shakesperiano este elemento es fácilmente reconocible ya que hay una mascarada propiamente dicha. La presencia no es tan directa en la obra de Mann. En este caso, el juego es macabro y relaciona personajes reales y ficticios pertenecientes al mundo interior de Aschenbach.

\section{Exotismo veneciano}

Como ya se ha mencionado anteriormente, el hecho de que Venecia posea ese carácter foráneo, a pesar de estar en Europa, la dota de cierto misticismo. La posibilidad de liberación sexual en este ambiente exótico es otro punto que justifica que la ciudad sea la protagonista. La presencia de una temática sexual es otro de los elementos fundamentales de las obras del dramaturgo inglés. Shakespeare utiliza la temática homosexual en sus Sonetos, escritos y publicados en la misma época que El mercader de Venecia. El préstamo de Antonio para ayudar a su idolatrado Bassanio propicia el 
lanzamiento de la trama y permite que diferentes razas y religiones interactúen.

Su declaración amorosa presenta una dualidad en el comportamiento del cristiano Antonio. Por una parte, la aceptación de su destino y su entrega a la muerte entronca con la figura del mártir, ya que está dispuesto a morir por responsabilizarse de la deuda de Bassanio. No obstante, por otro lado, hay una homosexualidad subyacente que no tiene cabida entre sus creencias religiosas. Es un católico extraordinario que encarna todas las características necesarias para ser un buen cristiano. Sin embargo, tiene uno de los pecados más castigados por la Iglesia Católica. La figura del buen cristiano queda anulada por el carácter pecaminoso de su condición sexual. Holdernes hace referencia al comportamiento de Antonio: "As a homosexual man, Antonio is again linked with Shylock. In the Divina Comedia Dante placed usurers and sodomites in the same circle of hell, on the basis that both sins represented 'unnatural' way of doing a 'natural thing'" (Holdernes 2010: 72). No hay salvación para la figura del mercader, sus deseos sodomitas le condenan irremediablemente al infierno.

El sentimiento amoroso que siente Gustav hacia el joven no es tan puro como el de Antonio. El vínculo entre Aschenbach y Tadzio obedece a la necesidad del artista por encontrar la inspiración necesaria que le ayude a continuar con su obra. Además, el viejo artista únicamente resalta los rasgos de Adonis del joven. Mientras que Antonio espera tener una relación de carácter amoroso con Bassanio, Aschenbach quiere una relación de carácter sexual. Sin embargo, el alemán reconoce la imposibilidad de ejecutar dicha acción: "Musitó la fórmula fija del deseo, imposible en este caso, absurda, abyecta, ridícula $y$, no obstante, sagrada también aquí venerada: 'Te amo'" (Mann 1996: 68). Los sentimientos de Antonio por Bassanio y los de Aschenbach por Tadzio no son equiparables ya que esta declaración establece la diferencia entre el amor y el deseo carnal.

Por último, cabe resaltar que la similitud que presentan ambas relaciones homosexuales es que tanto Antonio como Aschenbach casi son aniquilados en el intento por conseguir sus fantasías. Las relaciones homoeróticas son castigadas en ambas novelas, mientras que las heterosexuales son fructíferas.

\section{Conclusión}

En definitiva, la mitificación de la ciudad de Venecia atiende a varios aspectos fundamentales e inherentes a dicho enclave como la presencia de los canales y su condición de lugar exótico a pesar de su pertenencia al continente europeo. La majestuosidad de la ciudad y su carácter atemporal quedan demostrados por el hecho de ser la protagonista de dos obras tan distantes en el tiempo y que plasman 
de manera fehaciente la realidad de la época a la que pertenecen ambos textos. El desarrollo económico de la ciudad en los siglos XVI y XVII contribuye a que sea el escenario elegido por Shakespeare. Sus conflictos raciales y su multiculturalidad muestran una urbe próspera, activa y en expansión. Dicha apariencia dista mucho de la presentada por Mann, donde la atmósfera decadente y un ambiente enfermizo destruyen silenciosamente la ciudad. Mann ofrece una visión pesimista que evidencia el deterioro del enclave por el paso del tiempo hasta convertirse en un lugar decrépito del que es difícil escapar.

Por último, la presencia de la máscara, icono veneciano por excelencia, actúa de manera dispar en ambas obras. Su incursión en la obra de Shakespeare tiene un doble sentido porque, además de representar una de las características de Venecia, es uno de los típicos artificios del teatro isabelino. Por otro lado, Mann se centra en la transgresión de esta mascarada para evidenciar la decadencia del continente europeo de principios del siglo pasado.

\section{Bibliografía}

BLOOM, Harold (2002): Shakespeare: La invención de lo humano. Barcelona: Anagrama.

BREGAZZI, Josephine (1999): Shakespeare y el teatro renacentista inglés. Madrid: Alianza Editorial.

FERNÁNDEZ, Jaime (2010): La ciudad de los extravíos: Visiones venecianas de Shakespeare y Thomas Mann. Madrid: Fórcola Ediciones.

HOLDERNES, Graham (2010): Shakespeare and Venice. Farham: Ashgate.

MANN, Thomas (1996): La muerte en Venecia, en Los premios Nobel de la literatura. Barcelona: Plaza \& Janés.

SHAKESPEARE, William (2001): The Merchant of Venice. London: Penguin Editorial.

TOSI, Laura; \& BASSI, Saul (2011): Vision of Venice in Shakespeare. Farham: Ashgate. 